\title{
Attenuation of TNT in Seawater Microcosms
}

\author{
I. Harrison \& C. H. Vane* \\ British Geological Survey, Kingsley Dunham Centre, \\ Keyworth, Nottingham, NG12 5GG, U.K. \\ *Corresponding author. Tel+44 (0)115 936 3017; fax+44 (0)115 936 3329. E-mail \\ address: chv@bgs.ac.uk
}

Abstract

The ability of two differing marine sediments (one clayey, the other sandy) to attenuate the explosive 2,4,6-trinitrotoluene (TNT), dissolved in intertidal seawater from the eastern English coast of the North Sea, was examined using aerobic microcosms. Analysis of the seawater from the microcosms revealed an initial sharp decline in TNT concentration with clayey sediment in both sterilized (to prevent microbial activity) and unsterilized microcosms. This effect did not occur to such a marked extent in similar sterile and non-sterile sandy sediment microcosms and was attributed mainly to sorption of TNT to the fine clay particles of the clayey sediment. As time progressed, the attenuation of TNT in microcosms containing either type of sediment was found to be less in those that had been sterilized compared with those where microbial action proceeded unhindered. Feeding the microcosms, (i.e. supplying extra carbon sources for the microbial communities), appeared to have a small, but perceptible, enhancing effect upon TNT dissipation. The attenuation of TNT was also measured in large microcosms containing 2.5L of seawater and no 
sediment. Analysis of the seawater revealed a gradual decline in TNT concentration in non-sterile and fed microcosms compared to their sterile counterpart. Overall, this laboratory study showed that the attenuation of TNT is slow (half-life in seawater ca.1900 days; half-life sand sediment $<700$ days; half life in clay sediment 130 days) under conditions commonly encountered in coastal waters of the North Sea.

Keywords: Explosives, 2,4,6-trinitrotoluene, aerobic, microcosms, sorption, abiotic, microbially-mediated degradation.

\section{Introduction}

The main conventional explosive employed globally by military forces in the last century was 2,4,6-trinitrotoluene (TNT). Throughout the world, it has been extensively released to the environment during manufacture, deployment and disposal (Talmage et al., 1999). Even though the contamination of the marine environment by munitions has not generally been well documented (Cruz-Uribe et al., 2007), it is well known that substantial dumping of UXO (unexploded ordnance) at sea has occurred worldwide with considerable amounts deposited in the North Sea. This area is covered by the Oslo/Paris agreement which provides a legal framework for the protection of the marine environment of the North-East Atlantic (OSPAR, 2005). Additionally, explosives contamination emanating from military ranges is recognised 
to be an international problem (Clausen et al., 2004). Little appears to have been published on the situation in the UK, but it would seem safe to assume that ranges in the UK suffer similar contamination issues to those documented for Canada and the USA (Jenkins et al., 2006; MacDonald, 2001). There are some 140 defence sites on the UK coast and these are predominantly used for live firing or explosive trials (Coulson \& Brooks, 2006). Because of the relative ease of sampling, we opted to obtain intertidal seawater from the eastern English North sea coast and determine its ability to attenuate TNT and so derive an indication of the ability of intertidal seawater to mitigate the well-documented toxic threat to littoral benthic organisms that TNT poses (Ek et al., 2007; Green et al., 1999; Lotufo et al., 2001; Rosen \& Lotufo, 2005; Rosen \& Lotufo, 2007; Won et al., 1976). In general, these toxicity studies using nitrotoluene compounds have reported that toxicity decreases as the extent of nitrogenation falls, thus TNT is more toxic to marine organisms than DNT. Laboratory investigations aimed at developing marine toxicity data for a range of ordnance compounds gave LOEC (lowest effect concentrations) survival endpoints values of $1.34 \mathrm{mg} / \mathrm{L}$ Mysid, $10.8 \mathrm{mg} / \mathrm{L}$ Redfish Lavae and $11.6 \mathrm{mg} / \mathrm{L}$ Polycheate (Nipper et al., 2001). It has also been established that a crtitical body burden of 83 to $172 \mu \mathrm{mol} / \mathrm{kg}$ for marine amphipod Eohaustorius Estuarius and that the median effective concentration (EC50) values of Mytillus galloprovincialis (Mediterranean Mussel) of 0.75 and $19.5 \mu \mathrm{mol} / \mathrm{L}$ for larval and adult stages respectively (Rosen \& Lotufo, 2005). 
The main aim of this study was to assess the ability of seawater, either with or without sediment present, to attenuate TNT under conditions similar to those encountered in the eastern English North sea coast.

\section{Material and methods}

\subsection{Sampling and Microcosm Preparation}

Intertidal seawater was collected on January $6^{\text {th }} 2009$ from the North Sea at Anderby Creek, Lincolnshire, UK. Stored in $2.5 \mathrm{~L}$ sterilised amber glass bottles, it was transported to the laboratory in cool boxes and stored in an incubator at $7.0^{\circ} \mathrm{C} \pm 0.1^{\circ} \mathrm{C}$. Immediately before use the oxygen status of the seawater was determined, by Alsterberg’s modified Winkler titration (Rodier, 1975), to confirm its aerobic nature and, thereby, validate the use of aerobic microcosms as appropriate for the TNT attenuation study. The dissolved oxygen content $\left(\mathrm{dO}_{2}\right)$, under these conditions, was found to be $8.04 \mathrm{mg} / \mathrm{L}$ which was comparable with other published determinations. Thus, the dissolved oxygen content of North Sea water has been reported and, for diverse locations measured in both summer and winter, bottom waters were found to range between $6.0 \mathrm{mg} / \mathrm{L}$ and $11.3 \mathrm{mg} / \mathrm{L}$ (Lohse et al., 1996). Coastal surface water in the Southern Bight of the North Sea gave a range $7.1 \mathrm{mg} / \mathrm{L}$ to $12.6 \mathrm{mg} / \mathrm{L}$ for measurements made both in summer and winter (Frankignoulle et al., 1996). 
The two marine sediments investigated were a fine-grained clayey sediment (Sediment A) and a coarse-grained sandy sediment (Sediment B). The sediments were collected on May $2^{\text {nd }} 2008$ from the North Sea using a Day Grab, the sediments had the following characteristics:

Sediment A (Clayey) : $\quad$ Sand $14.4 \%$, Clay 19.5\%, Silt $66.1 \%$ and TOC $2.23 \%$ Sediment B (Sandy) : $\quad$ Sand 92.5\%, Clay $\quad 2.0 \%$, Silt $\quad 5.5 \%$ and TOC $<0.10 \%$

For spiking the microcosms a saturated solution of TNT in seawater was prepared by weighing $300 \mathrm{mg}$ of TNT into 2 litres of seawater. TNT is cited as having a solubility of $140 \mathrm{mg} / \mathrm{L}$ in pure water at $25^{\circ} \mathrm{C}$ (Gorontzy et al., 1994), but it is less soluble in saline waters (Prak \& O'Sullivan, 2006). The mixture was periodically inverted and shaken over three hours then left to stand.

The effect of supplying additional carbon sources was studied to some of the microcosms to see if these might enhance microbially-mediated TNT degradation. Given that the dissolved organic carbon content (DOC) of North Sea water is ca. 2.5 mg/l (Ferrari, 2000), an additional $2.5 \mathrm{mg} / \mathrm{L}$ DOC was added to create the 'fed' microcosms. For this purpose a concentrated feeding solution, containing $25 \mathrm{~g} / \mathrm{L}$ of DOC, was prepared by dissolving 0.284 g sodium acetate trihydrate, 0.147 g 85\% DL-lactic acid, 0.128 g glycerol, 0.125 g D-glucose, 0.123 L-glutamic acid in sterile pure water, and adjusting the $\mathrm{pH}$ of the resulting solution to 8.0 (i.e. the $\mathrm{pH}$ of the collected seawater) with sodium hydroxide solution before making to $10 \mathrm{ml}$. Each component was calculated to contribute $5 \mathrm{~g} / \mathrm{L}$ of DOC to the concentrate and all were chosen after due consideration of the relevant literature on marine microbiology 
(Baumann et al., 1972; Donderski et al., 1998; Eilers et al., 2000; Hagstrom et al., 2001; Jannasch, 1967; Jannasch, 1968; Jannasch, 1969). Fed microcosms were made from either sterile or non-sterile seawater that contained $110 \mu \mathrm{l} / \mathrm{L}$ of the $25 \mathrm{~g} / \mathrm{L}$ feeding concentrate. When made to their final volume in the microcosms this gave $2.5 \mathrm{mg} / \mathrm{L}$ of added DOC.

Microcosms, whose contents had been sterilised by the addition of sodium azide, were compared to similar microcosms that contained no sterilant to permit an assessment of the contribution of microbially-mediated degradation. Sterile seawater was prepared by adding $2.22 \mathrm{~g} / \mathrm{L}$ of sodium azide to some of the collected seawater. Once the microcosms were made up this gave a final sodium azide concentration of $0.2 \% \mathrm{w} / \mathrm{v}$ a level at which azide has been shown to act as an effective biocide (Harrison et al., 2003). To make allowance for the effect of azide addition upon sodium content, the seawater to be used for the non-sterile microcosms was similarly adjusted by the addition $2.00 \mathrm{~g} / \mathrm{L}$ of sodium chloride. Given the overall salinity of seawater from the North Sea varies between 3.10\% and 3.52\% (Jones \& Howarth, 1995), the influence of these additions on the ionic strength of the seawater was deemed negligible. One limitation of this study was that the sterility of samples was not checked by microbial plate counts. Alternative measures to sterilize the microcosms by for example ${ }^{60} \mathrm{Co}$ irradiation were not conducted, thus complete microbial inhibition cannot be completely shown. A second limitation of this study was that no metabolites were measured. 
Six sets of sacrificial microcosms (SMs) were constructed with 12 microcosms per set. Each microcosm consisted of a sterilised $60 \mathrm{ml}$ amber glass bottle containing $2 \mathrm{~g}$ of marine sediment together with $40 \mathrm{ml}$ of sterile or non-sterile seawater, either fed or unfed. The solution to solid ratio was accordingly 20:1, similar to the 18:1 ratio previously employed for the determination of environmental process descriptors for TNT (Yost et al., 2007).

SMs 1: UAN (Sediment A, Unfed non-sterile seawater)

SMs 2: UAS (Sediment A, Unfed sterile seawater)

SMs 3: FAN (Sediment A, Fed non-sterile seawater)

SMs 4: FAS (Sediment A, Fed sterile seawater)

SMs 5: FBN (Sediment B, Fed non-sterile seawater)

SMs 6: FBS (Sediment B, Fed sterile seawater)

Once prepared, the microcosms were left to acclimatize for 45 days in the incubator at $7^{\circ} \mathrm{C}$. This temperature was selected to approximate typical winter sea surface and coastal bottom temperatures, in the North Sea (Becker \& Pauly, 1996; Lane \& Prandle, 1996; O'Brien et al., 2000). Following acclimation, the microcosms were each spiked with $4 \mathrm{ml}$ of the saturated TNT in seawater, shaken and returned to the incubator. The initial TNT concentration was derived by spiking 4 $\mathrm{ml}$ of the saturated TNT into $40 \mathrm{ml}$ seawater, with no sediment present, and immediately analysing the resulting solution by High Performance Liquid Chromatography (HPLC). A value of $10.02 \mathrm{mg} / \mathrm{l}$ was obtained for the TNT 
concentration by analysis of this sample. The uncertainty in the analysis at this concentration, for a 95\% confidence level, was calculated to be $0.94 \%$.

Additionally, four large microcosms (LMs) were constructed in $2.5 \mathrm{~L}$ amber bottles that contained no sediment.

LM 1: UN (Unfed non-sterile seawater) (2 L seawater + $220 \mathrm{~mL}$ saturated TNT)

LM 2: $\quad$ US (Unfed sterile seawater) (2 L seawater $+220 \mathrm{~mL}$ saturated TNT $+4.44 \mathrm{~g}$ sodium azide)

LM 3: $\quad$ FN (Fed non-sterile seawater) (2 L seawater $+220 \mathrm{~mL}$ saturated $\mathrm{TNT}+220$ $\mu$ feed concentrate)

LM 4: $\quad$ FS (Fed sterile seawater) $(2 \mathrm{~L}$ seawater $+220 \mathrm{~mL}$ saturated TNT $+220 \mu \mathrm{l}$ feed concentrate +4.44 g sodium azide)

The LMs were also placed in the incubator and both LMs and sacrificial microcosms were inverted and shaken to suspend the sediment once a day. Periodically, the LMs and sacrificial microcosms were sampled by taking $0.5 \mathrm{ml}$ in a glass GT (gas-tight) syringe for HPLC analysis. Once a week the headspace air in all microcosms was exchanged for fresh, filtered (Whatman Hepa-Vent) air to ensure the maintenance of aerobic conditions. All the chemicals referred to in this section were obtained from Sigma-Aldrich UK except for TNT which was supplied by Greyhound Chromatography \& Allied Chemicals, UK.

2.2 High Performance Liquid Chromatography (HPLC) Analysis 
Samples of $0.5 \mathrm{ml}$, taken from either the sacrificial microcosms or the LMs, were $0.2 \mu \mathrm{m}$ filtered (Millex - $4 \mathrm{~mm}$ nylon 66 in-line syringe filters) during injection through the $100 \mu \mathrm{l}$ sampling loop (Rheodyne) installed on the HPLC system. A

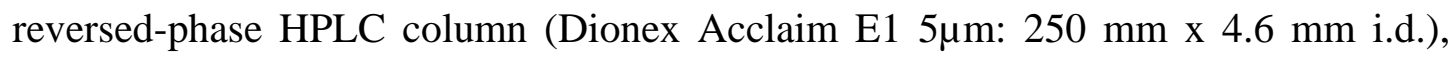
maintained at $38^{\circ} \mathrm{C}$ by a column oven (Grace/Vydac 7995R), was used for the analysis. The mobile phase, composed of a mixture of $430 \mathrm{ml}$ of methanol (Rathburn UK) and $570 \mathrm{ml}$ water (MilliQ), vacuum degassed in-line (CSI 6150 Cambridge Scientific Instruments UK), was pumped at $1 \mathrm{ml} / \mathrm{min}$ (Merck-Hitachi Isocratic L6000 Pump). Detection was performed at $254 \mathrm{~nm}$ (TSP UV2000 Thermo-Separation Products). A five point calibration was found to be linear over the range $0-15 \mathrm{mg} / \mathrm{l}\left(\mathrm{r}^{2}=1.00\right)$. The calibration was conducted with a standard explosive mixture containing 14 nitroaromatic/nitramine components, each at $1 \mathrm{~g} / \mathrm{l}$ (Accustandard Inc. USA), suitably diluted using the $5 \mathrm{~g} / \mathrm{l}$ aq. calcium chloride dilution technique described in Method 8330 (USEPA, 1994).

\section{Results and Discussion}

Each of the LMs (no sediment), containing a total initial volume of $2.22 \mathrm{~L}$, was sampled a total of seven times with $0.5 \mathrm{ml}$ being taken for each sample. Thus, 3.5 ml was eventually removed from each. Unlike the SMs, where sediment was present, the repeated removal of small samples from the LMs was considered justified since the small reduction in volume from repeated sampling would not affect the 
overall liquid to solid ratio (there being no solid except for the glass walls of the LMs). The results from the periodic sampling of the LMs over 163 days are presented in Fig. 1. Exponential curve fitting to the graphs appearing in Fig.1 produced the data for the LMs that are displayed in Table 1.

Inspection of Fig. 1 revealed that there were small decreases in TNT concentrations over the period for all the no-sediment microcosms. The pseudo first-order rate constant $(k)$ for the sterile fed and unfed microcosms was 0.00041 day $^{-1}$ and 0.00020 day $^{-1}$ respectively (Table 1). Because the degradation in these microcosms was abiotic, it was probable that the losses of TNT were due to chemical reactions, but not photolysis, since the microcosms were maintained in the dark. Thus, for instance, TNT could have reacted with amino moieties of the proteinaceous material, and the dissolved combined amino acids (DCAA), known to be present in seawater (Keil \& Kirchman, 1993). Indeed, the reaction of TNT with amino acids to form Meisenheimer complexes has been proposed for use in the clean-up of TNT-contaminated soils (Fant et al., 2001). Since one of the components used for feeding the microcosm was an amino acid, (i.e. L-glutamic acid), this would account plausibly for the increased rate of TNT attenuation in the fed, compared with the unfed, microcosm. For the non-sterile fed and unfed microcosms $k$ was 0.00094 day $^{-1}$ and 0.00036 day $^{-1}$ respectively. That these rates were greater in comparison with their sterile counterparts reflects the contribution of the seawater's indigenous microbial community to the TNTs rate of disappearance. For the sterile LMs, $k$ of the fed is approximately double that of the unfed, whereas, for the non-sterile, $k$ of the 
fed is about 2.6 times that of the unfed, suggesting that feeding to some extent enhanced the activity of the microbial community.

For the sacrificial microcosms, each sample was taken from the incubator at a prescribed time and shaken. A $0.5 \mathrm{ml}$ sample was then taken immediately and injected into the HPLC via an in-line filter (see 2.2). Afterwards, the microcosm was discarded. This sacrificial strategy was instituted, in the case of microcosms containing sediment, because of the alteration to solid/solution ratios that would be imposed by multiple samplings. Duplicate microcosms, analysed on days 66, 89 and 116, confirmed that the microcosms could be relied on to behave reproducibly. Analysis of procedural blanks indicated that no perceptible interferences from materials with the same retention time as TNT occurred in the HPLC chromatograms.

It will be observed from Fig. 2, and from the data in Table 1, that attenuation of TNT in the sediment-based sacrificial microcosms (SMs) was much greater than for the corresponding no sediment-based LMs. All SMs, unlike LMs, had experienced an initial marked fall in TNT concentrations by the time they were first sampled after one day had elapsed. Because this only occurred in the SMs, where sediments were present, it implied that sediment was responsible for this effect. Also, it was far more pronounced for the clayey sediment than for the sandy sediment. It seemed likely, therefore, that the principal contribution to this rapid fall in TNT concentrations was sorption. TNT is known to adsorb strongly to clay minerals (Haderlein et al., 1996), and to sediment organic matter (Weissmahr et al., 1999). 
Also, it has been shown that these sorption processes can act very quickly for TNT when dissolved in either fresh or saline waters (Brannon et al., 2005).

Thereafter, the rates of TNT disappearance diminished. As for the LMs, non-sterile SMs produced greater attenuation of the TNT than did their sterile counterparts, presumably because of the added contribution of microbially-mediated TNT degradation. For the sandy sediment (Sediment B) in fed SMs, the rate of TNT dissipation was ca. 2.4 times faster in non-sterile microcosms $\left(k=0.00227\right.$ day $\left.^{-1}\right)$ than in sterile microcosms $\left(k=0.00095\right.$ day $\left.^{-1}\right)$. For the clayey sediment (Sediment A) in unfed SMs, dissipation was ca. 2.1 times more rapid in non-sterile conditions $(k=$ 0.00538 day $\left.^{-1}\right)$ than in sterile $\left(k=0.00261\right.$ day $\left.^{-1}\right)$. When the clayey SMs were fed, the attenuation rate in non-sterile conditions $\left(k=0.00638\right.$ day $\left.^{-1}\right)$ was again $c a .2 .1$ times that in sterile $\left(k=0.00305\right.$ day $\left.^{-1}\right)$. The continued loss of TNT from sterile microcosms after the initial marked sorption probably represents slower movement of the sorptive process towards a steady state coupled with slow abiotic losses from chemical reaction, with, for example, amino compounds as discussed for the LMs.

As with the LMs, feeding of the SMs appeared to provide some enhancement in the ability to attenuate TNT. For practical reasons (limited incubator space primarily), only fed SMs for the sandy sediment were constructed and it was assumed that the fate of TNT in unfed, sandy sediment microcosms might be inferred from the behaviour of the LMs (no sediment) and the SMs that were prepared using the clayey sediment. Fed SMs with the clayey sediment degraded TNT somewhat more rapidly than the comparable unfed SMs. Thus, under non-sterile conditions: fed $k=0.00638$ 
day $^{-1}$ and unfed $k=0.00538$ day $^{-1}$ - under sterile conditions: fed $k=0.00305$ day $^{-1}$ and unfed $k=0.00261$ day $^{-1}$. The slight enhancement for the abiotic removal rate of TNT from the fed sterile SMs, compared with the unfed sterile SMs, may possibly be due to the added TNT reaction with the L-glutamic acid used as a component of the feed. The more appreciable difference in rates for the non-sterile situation was probably attributable to increased microbially-mediated degradation of TNT as a result of feeding the microbial community. Had, therefore, unfed SMs (sterile and non-sterile) been constructed employing the sandy sediment (Sediment B), it seems reasonable to surmise that they would have degraded somewhat more slowly than their fed counterparts.

Because pseudo first order kinetics take the form:

$$
\ln \left(C_{0} / C\right)=k t \quad \text { where } C_{0}=\text { initial concentration }
$$

$$
t=\ln \left(C_{0} / C\right) / k \quad \text { and } C=\text { concentration at time } t
$$

When $C$ becomes half its initial concentration then $C_{0} / C=2$; i.e. at $\quad t=t_{1 / 2}$

Then $\quad t_{1 / 2}=\ln (2) / k \quad$ where $t_{1 / 2}=$ the half life

$$
=0.693 / k
$$

The derivation of half-lives affords an easily understood, and tangible perception, of how quickly the microcosms are capable of dissipating TNT (Table 1). Half -lives are, of course, inversely proportional to the pseudo first-order rate constants and it will be observed that they range from 109 days to 3465 days. 
There appear to be few published studies that concern the behaviour of TNT in marine sediment and natural seawater systems. In certain respects, the conduct of our study was comparable to that undertaken by Yost et al. 2007. They undertook a considerably more comprehensive investigation than ours, that included details on the attenuation of, not only TNT, but a further ten related nitroaromatic compounds in the presence of three separate marine sediments, each used at a solution/solid ratio of 18:1. However, they utilised an artificial, rather than a natural seawater, and then to produce a salinity of only $2 \%$. The striking difference, though, is the much faster degradation rates that they encountered compared to our study. They quote half-lives for TNT ranging from 35 hours to 60 hours compared with our sediment-based results that range between 109 and 729 days. In both this and their study, photolytic effects were eliminated by the maintenance of microcosms in the dark, however, Yost et al., 2007 conducted their experiments at room temperature $\left(\sim 24^{\circ} \mathrm{C}\right)$, whereas, ours were conducted at a considerably lower temperature, i.e. $7.0^{\circ} \mathrm{C} \pm 0.1^{\circ} \mathrm{C}$. Also, they provided continuous agitation to their microcosms in contrast to our intermittent, albeit regular shaking. Our aim, though, was to emulate conditions that may be experienced in the low intertidal, subtidal and neritic zones of the North Sea during winter, where limited to zero contact between sediment and seawater, (as simulated by the SMs and LMs, respectively), may be anticipated. In this context, attenuation of TNT would, on the basis of our results, appear to be very slow. Comparison of our work with theirs, clearly illustrates that differences in 
temperature and sediment/seawater contact exert considerable influence over the attenuation behaviour of the TNT in seawater.

The half-lives we have recorded accord with observations that have been made concerning the hydrolysis of TNT by seawater (Hoffsommer \& Rosen, 1973). In their study it was discovered that a filtered, concentrated solution of TNT in seawater (95 $\mathrm{mg} / \mathrm{l}$ ) - from an unspecified location - maintained at $c a .25^{\circ} \mathrm{C}$ and kept in actinic glass to preclude photolysis, produced $0 \%$ loss of TNT over a 108 day period.

The photolytic degradation of TNT by sunlight was not considered and it should be borne in mind that this would contribute significantly to the overall attenuation of TNT in clear shallow waters. It was observed, when the intertidal seawater was collected, that it possessed a degree of turbidity; a common feature of coastal seawaters (Aarup, 2002). Though some of this settled on standing, a large proportion remained in suspension (i.e. was colloidal or was of neutral buoyancy). Light is reduced to $1 \%$ of its surface intensity after penetrating ca. $10 \mathrm{~m}$ into a typical coastal seawater (Sumich \& Morrissey, 2004). This turbidity would serve to diminish substantially the contribution of photolysis to the degradation of TNT.

\section{Conclusions}

The study aimed in essence to be a focused and simplistic assessment of the ability of seawater, either with or without sediment present, to attenuate TNT. The North Sea coast of the UK, and its waters, have numerous sites at which UXO, 
including TNT, may potentially cause contamination problems. Accordingly, the rate of TNT attenuation is an important factor for gauging the effect of UXO pollution on littoral benthic organisms. The study sought to emulate conservative conditions and so coastal seawater winter temperatures were chosen together with limited agitation of sediments. Under such conditions, TNT was found to dissipate very slowly. This is in marked contrast to its rate of attenuation, with a variety of stirred sediments, in artificial seawater at $c a \cdot 24^{\circ} \mathrm{C}$ (Yost et al., 2007). In our study, the half-life of TNT in seawater not in contact with sediment was ca. 1900 days. In the presence of a sandy sediment the half-life was estimated to fall to $<700$ days and this was further reduced to about 130 days when a clayey sediment was present. Both microbial degradation and sorption were found to contribute to the attenuation. Supplying extra carbon sources to the indigenous microbial community had a slight enhancing effect on TNT biodegradation.

\section{References}

Aarup, T. 2002 Transparency of the North Sea and Baltic Sea - a Secchi depth data mining study. Oceanologia 44, 323-337.

Baumann, L., Baumann, P., Mandel, M. \& Allen, R.D. 1972 Taxonomy of Aerobic Marine Eubacteria. J. Bacteriol. 110: 402-429.

Becker, G.A., \& Pauly, M. 1996 Sea surface temperature changes in the North Sea and their causes. ICES J of Mar Sci. 53, 887-898. 
Brannon, J.M., Price, C.B., Yost S.L., Hayes, C. \& Porter, B. 2005 Comparison of environmental fate and transport process descriptors of explosives in saline and freshwater systems. Mar Pollut Bull. 50, 247-251.

Clausen, J., Robb, J., Curry, D. \& Korte, N. 2004 A case study of contaminants on military ranges: Camp Edwards, Massachusetts, USA. Environ. Pollut. 129: $13-21$.

Coulson, M. \& Brooks, R. Enhancing access to the coast - Ministry of Defence. Paper to the National Countryside Access Forum 17/05/06, p1.countryside.gov.uk/.../Coastal\%20Access\%20-\%20MOD\%20(NCAF)_tcm 2-29472.doc.

Cruz-Uribe, O., Cheney, D.P. \& Rorrer, G.L. 2007 Comparison of TNT removal from seawater by three marine macroalgae. Chemosphere 7, 1469-1476.

Donderski, W., Mudryk, Z. \& Walczak, M. 1998 Utilization of low molecular weight organic compounds by marine neustonic and planktonic bacteria. Pol $J$ Environ. Stud. 7 279-283.

Eilers, H., Pernthaler, J., Glockner, F.O. \& Amann, R. 2000 Culturability and In Situ Abundance of Pelagic Bacteria from the North Sea. Appl. Environ. Microb. 66, 3044-3051.

Ek, H., Nilsson, E., Birgersson, G. \& Dave, G. 2007 TNT leakage through sediment to water and toxicity to Nitocra spinipes. Ecotox. and Environ. Safe. 67, 341-348. 
Fant, F., De Sloovere, A., Matthijsen, K., Marlé, C., El Fantroussi, S. \& Verstraete W. 2001 The use of amino compounds for binding 2,4,6-trinitrotoluene in water. Environ. Pollut. 111, 503-507.

Ferrari, G.M. 2000 The relationship between chromophoric dissolved organic matter and dissolved organic carbon in the European Atlantic coastal area and in the West Mediterranean Sea (Gulf of Lions). Mar. Chem. 70, 339-357.

Frankignoulle, M., Bourge, I., Canon, C. \& Dauby P. 1996 Distribution of surface seawater partial $\mathrm{CO}_{2}$ pressure in the English Channel and in the Southern Bight of the North Sea. Cont. Shelf Res. 16, 395.

Gorontzy, T., Drzyzga, O., Kahl, M.W., Brunsnagel, D., Breitung, J., Vonloew, E. \& Blotevogel, K.H. 1994 Microbial-Degradation Of Explosives And Related-Compounds. Critical Rev. Microbiol. 20, 265-284.

Green, A., Moore, D. \& Farrar, D. 1999 Chronic toxicity of 2,4,6-trinitrotoluene to a marine polychaete and an estuarine amphipod. Environ. Tox. Chem. 18, 1783-1790.

Haderlein, S.B., Weissmahr, K.W. \& Schwarzenbach, R.P. 1996 Specific Adsorption of Nitroaromatic Explosives and Pesticides to Clay Minerals. Environ. Sci. Technol. 30, 612-622.

Hagstrom, A., Pinhassi, J. \& Zweifel, U.L. 2001 Marine bacterioplankton show bursts of rapid growth induced by substrate shifts. Aquat. Microb. Ecol. 24, 109-115. Harrison, I., Williams, G.M. \& Carlick, C.A. 2003 Enantioselective biodegradation of mecoprop in aerobic and anaerobic microcosms. Chemosphere 53, 539-549. 
Hoffsommer, J.C. \& Rosen, J.M. Hydrolysis of explosives in sea water. 1973 B Environ. Contam. Tox. 10, 78-79.

Jannasch, H.W. 1967 Growth of marine bacteria at limiting concentrations of organic carbon in seawater. Limnol Oceanog 12, 264-271.

Jannasch, H.W. 1968 Growth characteristics of heterotrophic bacteria in seawater. J. Bacteriol. 95, 722-723.

Jannasch, HW. 1969 Estimations of bacterial growth rates in natural waters. J. Bacteriol. 99, 156-160.

Jenkins, T.F., Hewitt, A.D., Grant, C.L., Thiboutot, S., Ampleman, G., Walsh, M.E., Ranney., T.A., Ramsey, C.A., Palazzo, A.J. \& Pennington, J.C. 2006 Identity and distribution of residues of energetic compounds at army live-fire training ranges. Chemosphere 63, 1280-1290.

Jones, J.E. \& Howarth, M.J. 1995 Salinity models of the southern North Sea. Cont. Shelf Res.15, 705-727.

Keil, R.G. \& Kirchman, D.L. 1993 Dissolved combined amino acids: chemical form and utilization by marine bacteria. Limnol. Oceanog. 38, 1256-1270.

Lane, A. \& Prandle, D. 1996 Inter-annual variability in the temperature of the North Sea. Cont. Shelf Res. 16, 1489-1507.

Lohse, L., Epping, E.H.G., Helder, W. \& vanRaaphorst, W. 1996 Oxygen pore water profiles in continental shelf sediments of the North Sea: Turbulent versus molecular diffusion. Mar. Ecol-Prog. Ser. 145, 63-75. 
Lotufo, G.R., Farrar, J.D., Inouye, L.S., Bridges, T.S. \& Ringelberg, D.B. 2001 Toxicity of sediment-associated nitroaromatic and cyclonitramine compounds to benthic invertebrates. Environ. Tox. Chem. 20, 1762-1771.

MacDonald, J.A. 2001 Cleaning up unexploded ordnance. Env. Sci. Technol. 35, 372A-376A.

Nipper, M., Carr, R.S., Biedenbach, J.M., Hooten, R.L., Miller, K. \& Saepoff. S. 2001 Development of marine toxicity data for ordnance compounds. Arch. Environ. Contam. Toxicol. 41, 308-318.

O'Brien, C.M., Fox, C.J., Planque, B. \& Casey, J. 2000. Fisheries - Climate variability and North Sea cod. Nature 404(6774), 142-142.

OSPAR. 2005 Overview of past dumping at sea of chemical weapons and munitions in the OSPAR maritime area. OSPAR Commission: Biodiversity Series, Publication No. 2005/222(ISBN 1-904426-59-X), 1-13.

Prak, D.J.L. \& O'Sullivan, D.W. 2006 Solubility of 2,4-dinitrotoluene and 2,4,6-trinitrotoluene in seawater. J Chem. Eng. Data 51, 448-450.

Rodier, J. 1975 Determination of dissolved oxygen. Analysis of Water, John Wiley \& Sons Ltd.(ISBN 0-470-72934-1) 382-385.

Rosen, G. \& Lotufo, G.R. 2005 Toxicity and fate of two munitions constituents in spiked sediment exposures with the marine amphipod Eohaustorius estuarius. Environ. Toxicol. Chem. 24, 2887-2897. 
Rosen, G., \& Lotufo, G.R. 2007 Toxicity of explosive compounds to the marine mussel, Mytilus galloprovincialis, in aqueous exposures. Ecotox. Environ. Safe 68, 228-236.

Sumich, J.L., \& Morrissey, J.F. 2004 Chapter 1: The ocean as habitat. Introduction to the Biology of Marine Life: 8th Edition, Jones \& Bartlett Publishers, USA(ISBN 076373313X), 22-23.

Talmage, S.S., Opresko, D.M., Maxwell, C.J., Welsh, C.J,E., Cretella, F.M., Reno, P.H. \& Daniel, F.B. 1999 Nitroaromatic munition compounds: Environmental effects and screening values. Rev. Environ. Contam. Toxicol. 161, 1-156.

USEPA, 1994, Method 8330: Nitroaromatics and nitramines by high performance liquid chromatography (HPLC). Test Methods for Evaluating Solid Waste. Physical/Chemical methods., EPA Publication SW-846(3rd Edition - Final update II).

Weissmahr, K.W., Hildenbrand, M., Schwarzenbach, R.P. \& Haderlein, S.B. 1999 Laboratory and Field Scale Evaluation of Geochemical Controls on Groundwater Transport of Nitroaromatic Ammunition Residues. Env. Sci. Technol. 33, 2593-2600.

Won, W.D., DiSalvo, L.H. \& Ng J. 1976 Toxicity and mutagenicity of 2,4,-6-trinitrotoluene and its microbial metabolites. Appl Environ Microb 31, 576-580. 
Yost, S.L., Pennington, J.C., Brannon, J.M. \& Hayes, C.A. 2007 Environmental process descriptors for TNT, TNT-related compounds and picric acid in marine sediment slurries. Mar. Pollut. Bull. 54, 1262-1266. 


\section{Figure and Table Captions}

Fig. 1. Degradation Curves for Large Microcosms (LMs)

Fig. 2. Degradation Curves for Sacrificial Microcosms

Table 1. Regression coefficient $\left(\mathrm{r}^{2}\right)$, pseudo first-order rate constants $(k)$ and half-life $\left(t_{1 / 2}\right)$ for TNT attenuation in microcosms 

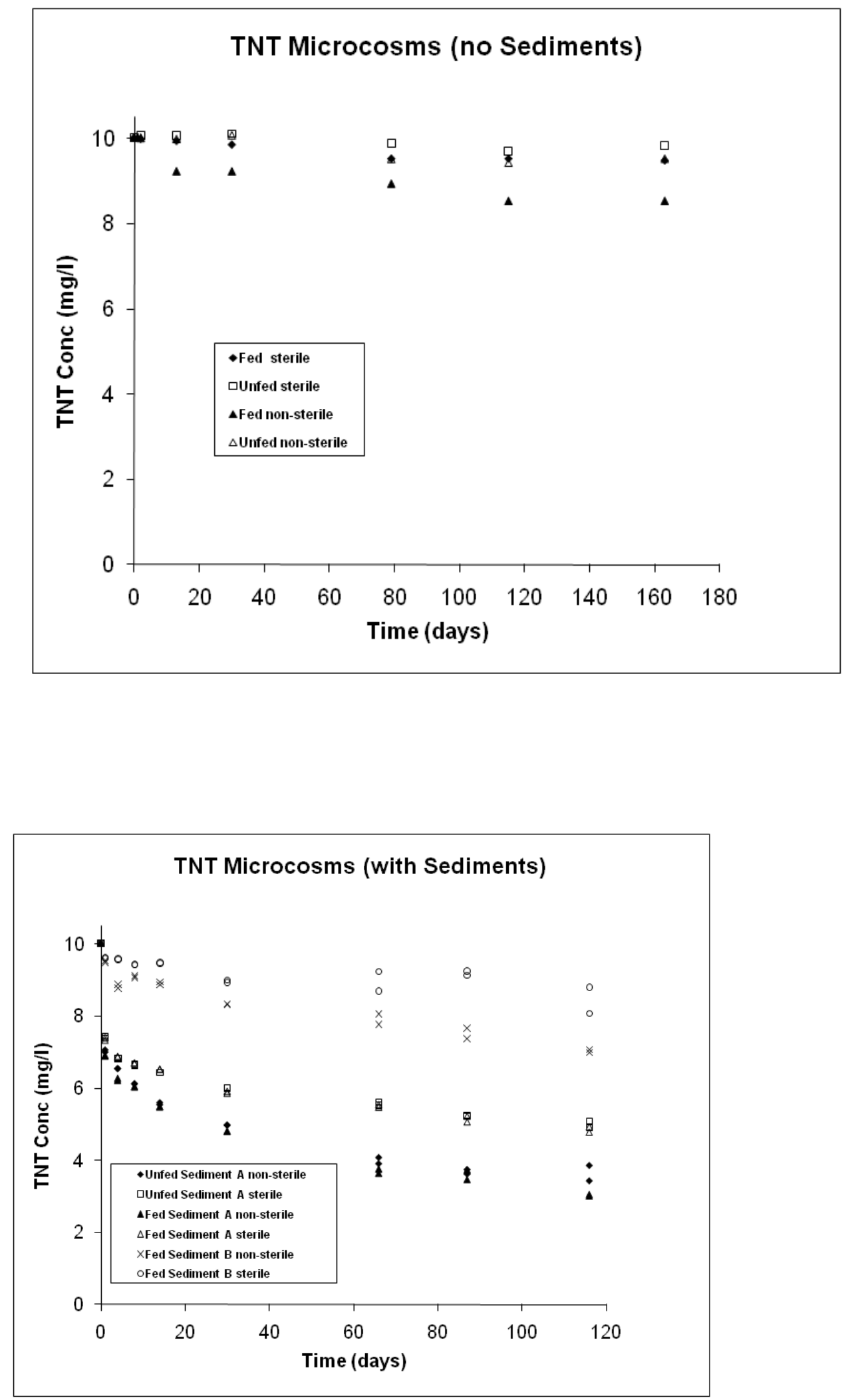


\begin{tabular}{|c|c|c|}
\hline $\begin{array}{c}\text { Micracasm } \\
\text { Type }\end{array}$ & $\mathbf{r}^{2}$ & $\begin{array}{c}k \\
\left(\mathrm{day}^{-1}\right)\end{array}$ \\
\hline \multicolumn{3}{|l|}{ L arge Micracasms (LMs) - nu sediment } \\
\hline US (Unfed, Sterile) & 0.70 & 0.00020 \\
\hline UN (Unfed, Non-sterile) & 0.88 & 0.00036 \\
\hline (Fed, Sterile) & 0.78 & 0.00041 \\
\hline (Fed, Non-sterile) & 0.81 & 0.00094 \\
\hline \multicolumn{3}{|l|}{ Sacrificial Micracasms - with sediments } \\
\hline FBS $\quad$ (Fed, Sediment B, Sterile) & 0.64 & 0.00095 \\
\hline FBN (Fed, Sediment B, Non-sterile) & 0.97 & 0.00227 \\
\hline (Unfed, Sediment A, Sterile) & 0.97 & 0.00261 \\
\hline (Unfed, Sediment A, Non-sterile) & 0.91 & 0.00538 \\
\hline (Fed, Sediment A, Sterile) & 0.96 & 0.00305 \\
\hline (Fed, Sediment A, Non-sterile) & 0.97 & 0.00638 \\
\hline
\end{tabular}

